\title{
"No comprar sin visitar la Casa Apolinar". La empresa de muebles de Apolinar Marcos
}

\section{'Don't buy without visiting the House of Apolinar': the furniture firm of Apolinar Marcos}

\author{
Sofía Rodríguez Bernis \\ Museo Nacional de Artes Decorativas, Madrid
}

\section{RESUMEN}

En este artículo se repasa la actividad comercial de la firma madrileña Apolinar Marcos en sus dos etapas principales, a partir de la exhumación de su archivo personal que incluye proyectos de decoraciones y muebles, modelos, láminas, fotografías y dibujos propios, ofrecidos como catálogos. Se repasan los métodos de aprovisionamiento de materiales, el sistema de adquisición de piezas y conjuntos a otras compañías, la amplia red de proveedores incluso de fuera de España, que le enviaban género a modo de muestrarios o depósitos, y su método usual de venta.

Palabras clave: Mobiliario, Firmas comerciales, Madrid, Primera mitad siglo xx, Métodos de fabricación y venta de muebles.

\section{SUMMARY}

This study deals with the commercial activities of the Madrid firm Apolinar Marcos during its two main stages, through the use of their archive containing projects for interior decoration and furniture, models, prints, photographs and drawings used as catalogues. The methods employed for obtaining materials, the system of acquiring individual and groups of pieces from other firms, the wide range of suppliers - even outside of Spain - that sent pieces as samples or on deposit, and their habitual sales methods are discussed.

Key words: Furniture, Commercial Firms, Madrid, First Half $20^{\text {th }}$ Century, Methods of Manufacture and Sale of Furniture. 


\section{INTRODUCCIÓN}

Apolinar Marcos Clemente (¿?-1936) fue un conocido mueblista madrileño y un personaje influyente que llegó a ostentar el cargo de concejal suplente del Ayuntamiento de Madrid en 1927. Su producción y actividades comerciales están bien documentadas en el archivo que conservan sus descendientes en la Fundación Fernando de Castro. Asociación para la Enseñanza de la Mujer', compuesto por proyectos de decoraciones y muebles que se pueden fechar entre la primera década del siglo xx y los años cincuenta, un libro de contabilidad que incluye los años 1908 y 1909, láminas sueltas de mobiliario procedentes de distintas publicaciones que sirvieron de inspiración a los dibujantes de la casa, fotografías, algo de correspondencia y abundantes facturas de suministradores; éstas últimas discurren entre 1920 y 1940, con un silencio en 1937 y 1938. En suma, un acervo muy rico que ilustra el procedimiento de trabajo de una empresa dedicada a las artes industriales, típica del primer tercio del siglo Xx, el carácter de sus producciones y su sistema de comercialización ${ }^{2}$.

Hasta los años ochenta del siglo XIX los talleres y las pequeñas industrias que iban incorporando máquinas herramienta eran, en general, muy modestas en número de trabajadores y en volumen de producción. La competencia del extranjero, sobre todo en lo que respecta a la fabricación de los productos por entonces englobados en la denominación "artes industriales", codiciados por las clases medias y altas, estrangulaba las iniciativas españolas. Francia en primer lugar, y en menor medida Inglaterra, Alemania y Austria, procuraban a los españoles mobiliario, vidrio y cristal, porcelana y loza, papeles pintados, moquetas, tejidos y tapicerías, metales manufacturados y, en general, objetos para la decoración a precios que iban desde los altos a los módicos. Era "incontestable [la] autoridad que le concede [a Francia] su abolengo en el progreso artístico, y la sólida reputación conquistada desde larga fecha en cuanto al refinamiento y depurado gusto con que saben presentar sus manufacturas" (Alzola 2000: 47).

Los gobiernos españoles no entraron de forma seria en la lucha euro-

\footnotetext{
${ }^{1}$ Fundada en 1870 por Fernando de Castro, se dedicó a la docencia dirigida a las mujeres, con el objetivo de procurarles una educación que les permitiera independencia intelectual y económica, gracias a las destrezas impartidas por sus escuelas de secretariado, taquigrafía y mecanografía, y telegrafía.

${ }^{2}$ El Fondo Apolinar se halla reunido en cajas de archivo, pero todavía no se ha catalogado ni siglado, debido a que la riqueza del Archivo y de la Biblioteca exigen un trabajo considerable a su archivero. Por esta razón las citas serán anárquicas. Para la mayor parte de los materiales documentales se citará la fecha a modo de referencia.
} 
pea de la competencia, para proteger las producciones nacionales y tratar de conquistar mercados extranjeros, hasta fines del siglo xix. Durante la segunda mitad de la centuria, y para alentar los progresos industriales, se fomentaron, con altibajos, la publicación de revistas y monografías de carácter técnico ${ }^{3}$, la celebración de exposiciones y concursos de bienes de consumo $^{4}$, la asistencia a las exposiciones universales de los industriales españoles y la mejora del sistema de las enseñanzas, en particular de las llamadas artísticas. La política arancelaria fue, durante décadas, perjudicial para los fabricantes nacionales; las rebajas establecidas en la base quinta de la Ley de 1869 tuvieron como consecuencia el cierre de muchas manufacturas y la moderación del ritmo de fabricación de otras. Hubo que esperar a 1891 para que un nuevo arancel proteccionista creara un clima de seguridad que consolidara la tendencia generalizada a la multiplicación de empresas del sector. En este caldo de cultivo favorable comenzó Apolinar Marcos sus negocios.

\section{Historia de la FÁBricA. PRIMERA ÉPOCA}

La fundación de la firma Apolinar Marcos (o Casa Apolinar), que se remonta a fines de los años ochenta del siglo XIX, debió tener lugar en torno a 1885. Durante los primeros años, su propietario se dedicó al comercio y la distribución de madera para pasar, en un momento indeterminado, a producir sus propios artículos. La fábrica de muebles se estableció en la calle Buenavista 37 -y durante poco tiempo también en Zurita 32-, y la tienda en el número 1 de la de las Infantas5.

El libro de contabilidad mencionado más arriba se escribió en un momento clave de transición y crecimiento. Muestra cómo la empresa pasó de vender la mayoría de los muebles que fabricaba a distribuidores con nombre propio y a "almacenistas residentes en esta Corte", a despachar casi toda

${ }^{3}$ Vieron la luz, aunque muchas no disfrutaron de larga vida, Los Anales de la Construcción y de la Industria, La Semana Industrial, La Gaceta Industrial, La Ciencia Eléctrica y otras de menor relevancia.

${ }^{4}$ Tras la celebración de algunas exposiciones no muy ambiciosas, en 1871 el Fomento de las Artes convocó una muestra local, a la que siguieron las de 1873, ya de carácter nacional, 1875, 1877 y 1883, organizadas por diversas instituciones y agrupaciones privadas. Las que sin duda pusieron a España a la altura europea fueron la Exposición Universal de Barcelona (1888), que transformó una zona de la ciudad, y la Exposición Nacional de Industrias Artísticas, e Internacional de Reproducciones (Barcelona, 1892).

5 El edificio, que era propiedad del Conde de Romanones, amigo de Apolinar, fue adquirido con posterioridad. Sólo se conserva un anteproyecto de la portada fechado ya en 1957. 


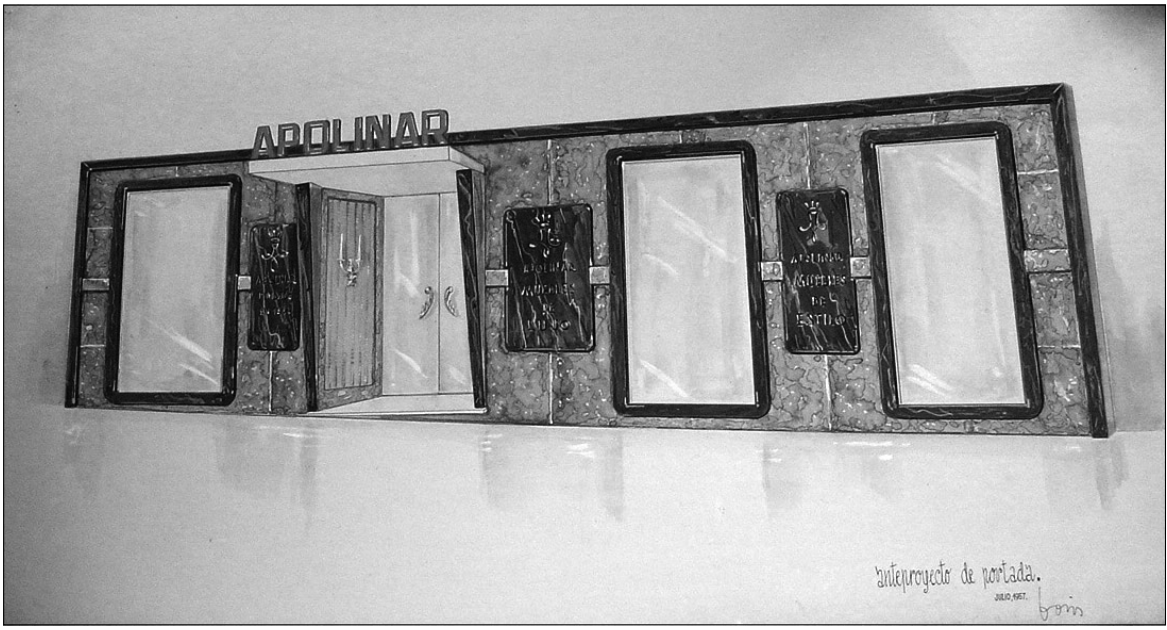

FIgurA 1. Fachada de la tienda de la calle de las Infantas.

su producción de forma directa a particulares a partir de enero de 1909. Este salto revela el éxito de sus creaciones y la decisión de adquirir una personalidad propia definitiva, una imagen de marca, como se diría hoy, avalada por la consolidación de la venta al detalle.

Los industriales a los que suministraba muebles Apolinar eran Felipa Frutos, Santiago López, Ignacio Morlans, Luis Somovila, Hijos de Grases, Godínez, Moreno y Compañía, Rufino Pinillos y Thonet Hermanos. La documentación que pueda ilustrar sus respectivas historias todavía no ha sido exhumada; Thonet Hermanos era la franquicia de una de las empresas más modernas y de mayor difusión del siglo XIX, fundada por Michael Thonet en Viena, especializada en muebles de madera curvada, que tenía tiendas en Madrid y en Barcelona (calle Pelayo 40). Además de las conocidas piezas caracterizadas por las curvas y contracurvas de su trazado, realizadas de forma industrial en haya moldeada al calor húmedo, ofrecían otras de gusto historicista, que son las suministradas por Apolinar y quizá por algún otro fabricante de muebles.

La venta de maderas, que fue el origen de su negocio, se mantiene en 1908, procurando ganancias modestas: 1.149,54 pesetas, frente a las 102.235,61 obtenidas por la venta de muebles. El comercio de madera desaparece del libro de contabilidad al año siguiente, en el que comienzan a mencionarse obras de carpintería de interiores ${ }^{6}$, si bien aún modestas, apuntando una vía de expansión que se desarrollaría más tarde.

\footnotetext{
${ }^{6}$ Se trata de las obras de carpintería de una tienda situada en la calle Tribulete, 1 (Libro de Cuentas, p. 157).
} 
Las cifras de ventas de 1908 y 1909 muestran un ligero descenso en el segundo año, resultante de la asunción del riesgo generado por la mayor independencia, aunque su volumen total es muy alto y revela la consolidación comercial y financiera de Apolinar. Si en 1908 la venta de muebles proporcionó 102.235,61 pesetas brutas, al año siguiente sólo procuró 66.019,5. Esta cifra no se debe interpretar como un fracaso, sino como el inicio de la etapa más brillante de la fábrica que, tras prescindir de intermediarios, pudo conquistar a título propio el favor de un público que no dejó de aumentar hasta 1936. Bien debieron marchar las cosas de forma inmediata, ya que la firma recibió, en 1915, un Diploma de Honor en el Concurso Nacional de Industrias, Comercios y Fábricas.

\section{Infraestructuras, equipamiento y suministros}

Si las ganancias eran elevadas también lo fueron los gastos de mantenimiento de la tienda y del taller. Los asientos fijos de los "gastos de casa" del libro de contabilidad incluyen los alquileres del taller y de la tienda, la contribución urbana, las facturas del teléfono y de la electricidad, los pagos del seguro de los obreros (a la sociedad Hispania) y las cuotas de la Beneficencia y el Círculo Mercantil, a los que se añaden otros extraordinarios del mismo tenor. Su cuantía es variada, y oscila entre las doscientas y las novecientas pesetas, si bien en una ocasión suben más porque se adquiere una estufa para el taller.

Las mercaderías se adquirían a distintas empresas. Los suministradores eran muy variados. Las maderas de pino se compraban en grandes cantidades a la Sociedad Belga del Paular, en tanto que otras procedían de Valsaín, donde en 1884 se había inaugurado el Real Taller de Aserrío Mecánico, con maquinaria belga e inglesa, que suministraba madera de sierra para obras de taller al mercado madrileño, además de piezas acabadas para la decoración de interiores ${ }^{7}$. Las cantidades de material registradas son abundantes, llegándose incluso en julio de 1909 a pagar "por portes, aforo y acarreo de

${ }^{7}$ Fabricaban entarimados, zócalos, jambas, cornisas, pilastras, medias cañas, molduras, guardavivos, bastones para cortinas, pasamanos y junquillos. Fue el primer taller que se mecanizó a gran escala, con un motor principal de vapor horizontal sistema Corliss, de 90 caballos, de la marca Prosper van der Kerchove (Gante), y calderas multibulares e inexplosibles del sistema Naeyer, de Villebroeck, también belgas; las máquinas de la sala de máquinas procedían en su mayoría de la casa Ransome de Londres, y eran casi todas sierras de diverso tipo — circulares, de cinta, verticales- cepilladoras, machihembradoras y molduradoras. Asimismo, contó con una pequeña herrería para las reparaciones. Exposición Universal de Barcelona. Catálogo razonado de los objetos expuestos por el Cuerpo de Ingenieros de Montes (Madrid, 1888). 
un vagón de madera de Valsaín, 216,20 pesetas". Para la adquisición de otras especies Apolinar recurría a comerciantes especializados: el castaño lo procuraba un tal Aparicio y el nogal, Rodríguez y Serrano, que también proporcionaba los artículos de ferretería. En los años de 1908 y 1909 no constan en el Libro de cuentas las especies más costosas, que sí figuran en el catálogo de los muebles vendidos, en macizo y, sobre todo, en chapeado: caoba fundamentalmente, satín o limoncillo de Indias y cedro; es posible que Apolinar conservara un buen repuesto de su época de comerciante en maderas 9 . Otros materiales que adquiría a otros fabricantes son las lunas de Viuda de Goya y de Guerra y Cía, para espejos de armarios y tocadores, los cristales para aparadores, los mármoles de Hijos de Almodóvar, de Alejandro Acero y de Cárcamo para tableros de aparadores y mesas, y los tejidos de Rodríguez Hermanos para las tapicerías de los asientos. Además, se procuraba palanganas y juegos de lavabo, colchones de muelles, asientos de rejilla y relojes que incorporaba a sus piezas y a sus conjuntos de piezas. La voluntad de encaminarse por el camino de la decoración empieza a apuntar ya en esta época.

\section{Los operarios y el sistema de trabajo}

Apolinar tenía en su taller un número estable de empleados, que parecen ser carpinteros y ebanistas en su totalidad, a los que pagaba semanalmente. Un oficial cobraba seis pesetas al día, y un ayudante, alrededor de dos. En los períodos de más trabajo los reforzaba con ayudantes y aprendices por jornadas o medias jornadas. Además, recurría a ciertos especialistas para decoraciones y acabados, a los que pagaba por cada intervención. Era, sin duda, más económico que incluirlos en plantilla. Se trataba de artesanos de pequeño taller, no de empresa, a los que la documentación identifica por sus nombres: el barnizador Ramírez, el tornero Emilio García y el tallista Ángel Crespo. El grabado de lunas se hacía también fuera.

A otros artífices se les encargan muebles ${ }^{10}$. Son todavía pocos, pero su presencia en las cuentas muestra el deseo de Apolinar de diversificar su

${ }^{8}$ Libro de cuentas, p. 179.

${ }^{9}$ Hay otros nombres de suministradores de maderas, como Vicente Lillo o Pedro Valdehita (que escribe Valdeita). Sólo a Nicomedes Herrero se le paga en una ocasión 612,50 pesetas por maderas sin especificar, quizá finas.

${ }^{10}$ En 1909 se paga a Miguel Escobar, "por dos góndolas Luis XV, 110 pesetas" (Libro de cuentas, p. 183), y a Cayuela, "por construcción muebles caoba, 125 pesetas"; "por construcción de sillas, 46" (id., p.193); y a un ebanista cuyo nombre no figura, "por la construcción de un comedor caoba y una mesa de despacho, 430 pesetas" (id., p. 197). 
oferta. En las facturas posteriores a 1920, como veremos, el número de fabricantes de muebles con catálogo propio que comercializa es ya muy numeroso.

El monto total de los jornales alcanza cifras considerables: en 1908 asciende a 32.153,25 pesetas, y en 1909 a 21.785,70. La diferencia a favor del primer año se explica porque, al dejar de suministrar géneros a otros mayoristas, Apolinar redujo el número total de empleados. A pesar de eso contrató un escribiente, cuyo sueldo mensual era de 30 pesetas, probablemente porque preveía que la gestión del negocio, ya dirigido mayoritariamente a particulares, se iba a hacer más compleja. Asimismo, comenzó a pagar a un fotógrafo que documentara sus creaciones, al que se llega a satisfacer la respetable cantidad de 163,90 pesetas en mayo de $1909^{11}$. Aunque la tienda contaba con una cierta cantidad de género manufacturado y listo para llevar, la mayor parte de las ventas se hacían por encargo, razón por la cual las fotografías debieron hacerse necesarias para mostrar al cliente la amplitud del catálogo. Para el mismo fin servían los dibujos, pocos todavía los de esta época.

Los portes para los particulares se realizaban con mozos de cuerda contratados para cada ocasión; por los embalajes se cargaba del 3\% al 6\% del precio total. Los de los mueblistas al por mayor no aparecen en las cuentas, ya que correrían por su cuenta, como era costumbre.

\section{Estilos y tipos de muebles}

Como ya era habitual por entonces, los muebles o los conjuntos de muebles - dormitorios, comedores y despachos principalmente- se identificaban con un número de catálogo. En estos años el de Apolinar llega a ofrecer un registro de casi cuarenta grupos de distinto tipo.

La firma apostó desde el principio por el historicismo consolidado desde el siglo XIX, opción conservadora que compartió con la mayoría de los fabricantes y comerciantes de bienes de consumo de la época. Su oferta fue, además, ecléctica y ajustada a las modas en boga en cada momento. La documentación de estos años tempranos manifiesta una declarada preferencia por el "estilo Luis XV", por el "Luis XVI" y por el "estilo inglés". De los dos primeros, que se repiten en los dormitorios y en sillerías de salón, se conserva un conjunto de dibujos, que son los de fecha más temprana de entre los del archivo. Reflejan el ornamento rococó y neoclásico, ligero, de trazos nerviosos y menudos, que se extendió en Francia hacia 1900, superpuesto a trazados de líneas sinuosas voladas, próximas al Art Nouveau, con

\footnotetext{
${ }^{11}$ Libro de cuentas, p. 197.
} 
algunas asimetrías de la misma filiación. El modernismo, más contenido y geométrico, se presenta en los muebles denominados "modernos", de línea escueta, "terminados de lunas y de cristales"12, muchas veces biselados perimetralmente, a la manera que pusieron de moda algunos de los diseñadores ingleses relacionados más o menos directamente con el movimiento Arts \& Crafts, como Bruce Talbert, y que luego tuvo continuidad en el modernismo sobrio de efecto bidimensional que se propagó por toda Europa, desde París a Berlín y desde Barcelona a Copenhague. El "estilo inglés" está emparentado con los revival británicos del siglo XIX, sobre todo con los "estilos" del XVIII y en particular con los que se distinguieron por el uso profuso de la pata cabriolé: el Reina Ana y el Chippendale ${ }^{13}$ o, por lo menos, la idea un tanto estereotipada que el historicismo tenía de ambos y que se popularizó en España a partir de $1895^{14}$.

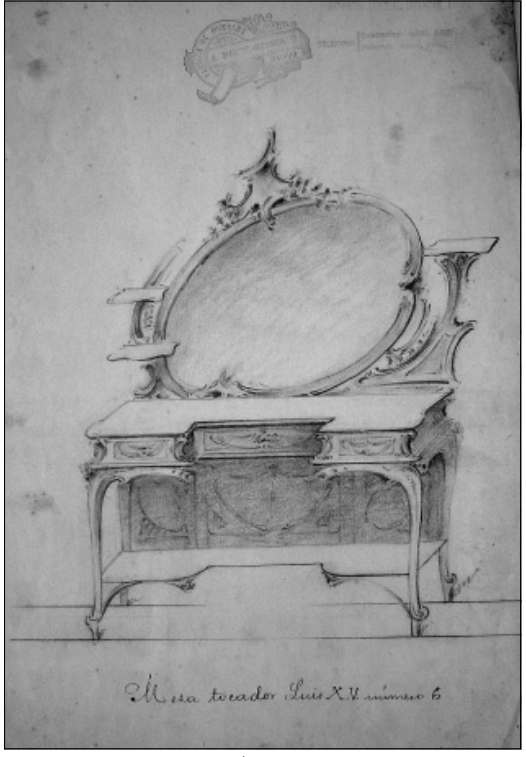

FIGURA 2. Tocador Luis $X V$, primer cuarto del siglo $\mathrm{XX}$.

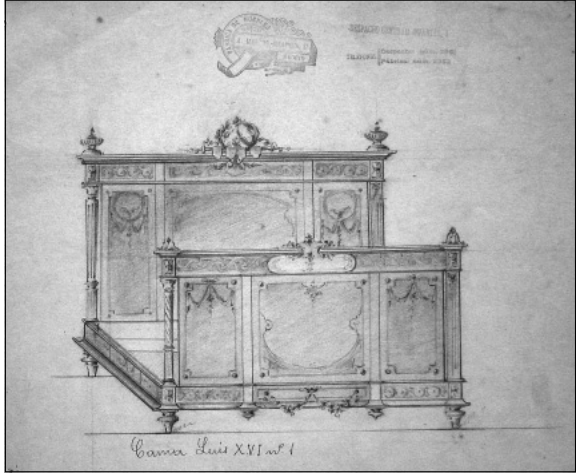

FIgura 3. Cama Luis XVI, primer cuarto del siglo XX.

12 "Un juego de despacho estilo Moderno n. 54 en caoba barnizada, terminado de lunas y cristales, compuesto de dos librerías, una mesa, tres sillones, cuatro sillas tapizadas en blanco", Libro de cuentas, p. 15.

13 "Un comedor estilo inglés n.. 39 en roble compuesto de chinero, trinchero, mesa de comedor y seis sillas, terminado de lunas y mármoles", Libro de cuentas, p. 33.

${ }^{14} \mathrm{El}$ Almanaque Bailly Baillière de 1895 dedica un artículo a "La historia del mueblaje" profusamente ilustrado con figuras de asientos de distinto tipo, entre los que figura un grupo "de caoba barnizada o de madera clara de estilo moderno" que reproduce modelos Chippendale, Sheraton y William Morris (p. 319). 


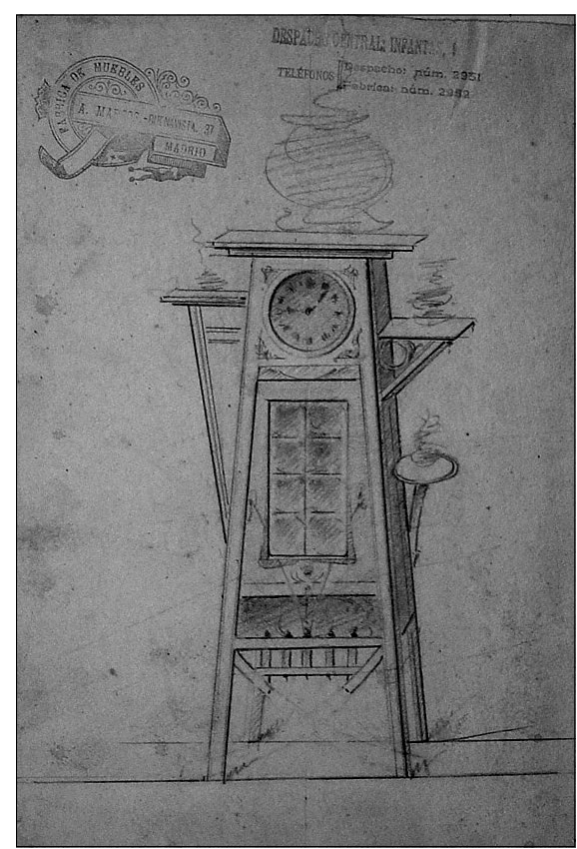

FIGURA 4. Sellette con reloj, "moderna".

A las corrientes internacionales se le añaden conjuntos "estilo Renacimiento", en proporción menor, pero tomando posiciones para un posterior ascenso de ventas fulgurante. Aunque el "estilo español", el que buceaba en las fuentes pretendidamente genuinas de la creación nacional, se remonta a los años setenta del siglo XIX - e incluso a fechas anteriores-, fue durante las dos primeras décadas del Xx cuando se concretó en la peculiar interpretación del Renacimiento y del Barroco que hoy se ha dado en llamar, en burlas, remordimiento, que tuvo larga vida.

Las maderas a veces se asocian a determinados estilos, como por ejemplo el satín —o limoncillo-, el roble y la caoba, a los ingleses y el nogal, al español; sin embargo, su elección se ajusta también al gusto y al bolsillo del consumidor: un "comedor estilo Renacimiento n. 032 en nogal y castaño" costaba 610 pesetas, y "otro idem en roble y castaño" ascendía a 450; el castaño se empleaba en la armadura y las otras maderas en las partes vistas ${ }^{15}$.

Las tipologías que se mencionan en la documentación de esta época, y que no varían sustancialmente hasta la Guerra Civil, son las que se estimaban necesarias para amueblar una casa completa, sin demasiadas fantasías pero incluyendo algunas piezas de adorno o de funcionalidad un tanto caprichosa. El conjunto estrella es el comedor, destinado a la estancia que en el último tercio del siglo XIX se había situado, en los pisos, junto a la sala, en la posición en la que mantiene todavía. Se componía de mesa - a menudo extensible o colisa -, sillas y dos aparadores: chinero y trinchero; el primero solía ser alto, de dos cuerpos, con compartimentos abiertos y cerrados para la vajilla, al modo de los grandes buffet a la francesa de la segunda mitad del siglo XIX; el segundo, de un solo cuerpo, derivado de los sideboards ingleses que se remontan al último cuarto del XVIII, contaba a lo sumo con un arrimadero superior de madera o con espejo. La combinación

\footnotetext{
${ }^{15}$ Libro de cuentas, p. 61.
} 


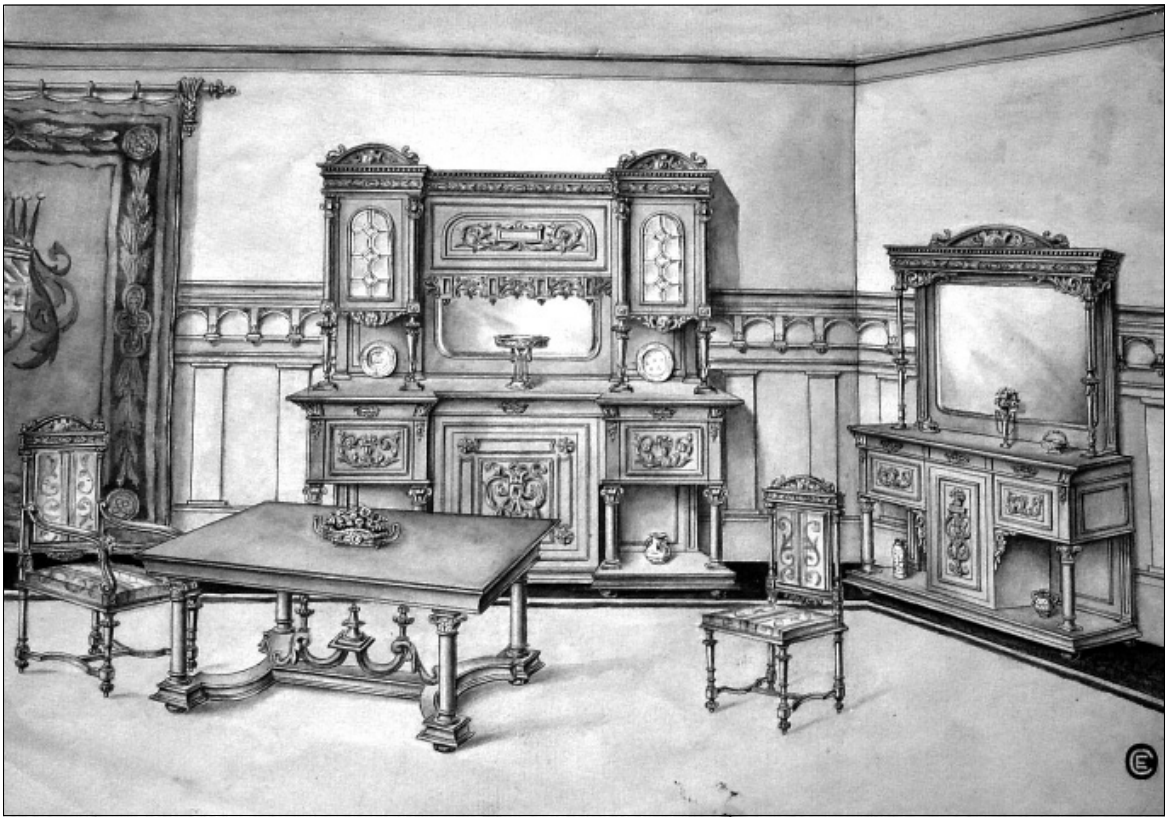

FIGURA 5. Comedor renacimiento, hacia 1920.

de ambos se había fijado ya en los años setenta del XIX. Después de la Gran Guerra, al aligerarse las masas de los muebles, se prefirió la combinación de dos trincheros, uno más amplio y corpulento que el otro, proceso que se observa con claridad en el catálogo de Apolinar.

Los dormitorios contaban con una cama de matrimonio, o con una o dos individuales, mesillas de noche, armario de luna, tocador y sillas - $\mathrm{Co}^{-}$ quetas o descalzadoras - El lavabo con palangana todavía se estilaba a principios de siglo, aunque fue abandonado a medida que el agua corriente se instaló en las casas pudientes, lo que permitió instalar el cuarto de baño, con lavabo integrado, junto al dormitorio. Mesas auxiliares y biombos para desnudarse castamente completan el conjunto, en el que tiene cabida, con carácter extraordinario, un escritorio de señora ${ }^{16}$.

El salón combina muebles más variados, entre los que destaca la sillería, a la que se añaden jardineras, que pasarán de moda después de 1915,

16 "Un dormitorio estilo inglés n.o 19 en caoba barnizada, interior roble compuesto de armario de tres lunas, cama de matrimonio, lavabo, dos mesas de noche, una mesa de tocador con espejo, una mesita auxiliar con tapa de luna, un biombo de 3 hojas y 4 sillitas a juego [...] más un espejo de chimenea en medida de luna de 156 x 96 haciendo juego a dichos muebles, un escritorio de señora a juego con pantalla de lunas y un silloncito coqueta". Libro de contabilidad, p. 37. 
y espejos. Apolinar no ofrece muchas más tipologías de sala, por lo menos en sus primeros tiempos. El despacho, por fin, consta de librerías, mesa, sillón y sillas.

Los muebles de Apolinar son para la burguesía de los pisos grandes y medianos. Son conjuntos para las piezas principales, no para las habitaciones de servicio. Tampoco comercia con las piezas propias de los palacetes de la aristocracia de sangre o del dinero, como las mesas de juego o de billar, los muebles de fumador o los comedores de gala.

\section{Historia DE LA FIRMA. SEgUNDA ÉPOCA}

El fondo documental del archivo Apolinar se interrumpe entre $1910 \mathrm{y}$ 1919; no así el conjunto de dibujos, entre los que se puede identificar un grupo realizado durante la segunda década del siglo.

Se conserva un abundante acopio de facturas de proveedores, fechadas entre 1920 y 1940, aunque ninguna relativa a los tratos de Apolinar con sus clientes, que muestran con precisión la evolución de la firma durante dos décadas. Entre 1920 y 23 el volumen de negocio era ya considerable, pero fue a partir de 1924 cuando se incrementó de forma regular hasta alcanzar su máximo desarrollo en torno a 1929. La bonanza perduró hasta la crisis de 1933 y 1934, años difíciles durante los que hubo que aplazar los pagos a varios proveedores; otros tuvieron que rogarle que hiciera lo propio con los suyos, afectados por las huelgas y la recesión de los encargos. La poca correspondencia que se conserva está relacionada con esta situación. En 1935 la firma experimentó un repunte —es quizá su año de mayor expansión-, que frustró la Guerra Civil: 1936 fue un año muy flojo, en el que los encargos cayeron en picado desde primavera y cesaron súbitamente cuando Apolinar fue asesinado en Paracuellos del Jarama y la fábrica incendiada. Parece que la firma permaneció cerrada en 1937 y 1938, hasta que en 1939 su hija Trinidad y su yerno, Rafael Muñoz-Yusta de Illara y Ruiz de Zárate, tomaron las riendas, reiniciando la venta y solicitando a los proveedores extranjeros que esperaran para cobrar facturas que habían quedado largo tiempo pendientes de pago. Una carta que el representante legal de la casa escribió a una fábrica alemana de guarniciones metálicas señala que "esta casa ha quedado totalmente esquilmada y sin una peseta" ${ }^{17}$. La recuperación fue dificultosa, como todo en aquella época. En 1939 apenas si se hicieron algunos arreglos y reparaciones de muebles. Una carta de 1940 al mueblista valenciano Salvador Blat dice: "aunque estamos en septiembre y parece que esto empieza a moverse algo, [este año] comercialmente ha sido malísimo,

\footnotetext{
${ }^{17}$ Carta de 22 de noviembre de 1939 a Bocklenberg, Motte $\& C^{o}$ mbh, Ronsdorf.
} 
hasta tal punto que todavía tengo tres alcobas de usted intactas, por lo que le agradecería que por ahora se abstenga de enviarme nada de género"18. A partir de entonces, y hasta los años cincuenta, el negocio siguió produciendo los diseños de la preguerra, según cuentan los descendientes de los fabricantes, y como lo indican anotaciones de fechas correspondientes a los años 40 realizadas al dorso de dibujos de décadas anteriores. Estos muebles seguían siendo muy del gusto de una burguesía media-alta, poco permeable a las novedades del diseño europeo, que sólo eran conocidas por un grupo de avanzados que muchas veces salieron de sus mismas filas. Además, el almacén acumulaba un abundante stock de piezas, a las que se dio salida progresivamente. Se conservan, asimismo, proyectos de amueblamiento y decoración de estos años, en gran parte de oficinas y despachos, algunos de gran envergadura.

\section{El sistema de trabajo. Los dibujos}

Entre 1909 y 1920 Apolinar había pasado de vender lo que fabricaba en sus talleres a distribuir, además, mobiliario de otros fabricantes. Los proyectos decorativos fueron asimismo una parte importante de su negocio.

Sabemos qué fabricaba, a partir de 1920, gracias a la colección de diseños y a las compras de materias primas y de guarniciones textiles y metálicas para sus muebles. Los varios centenares de dibujos conservados, que presentan muebles sueltos o conjuntos a juego, se mostraban al cliente, a modo de catálogo, para que hiciera sus encargos, por lo que son en extremo cuidados y se adecuan a los estilos de moda de la ilustración y del cartelismo, sobre todo a aquéllos que no se decantaban de forma franca por las rupturas formales de las vanguardias, sino por los modos de expresión plástica más decorativos y amables. La compra por encargo era a la carta: no hacía falta quedarse con todos los componentes de un conjunto, sino sólo con los que se necesitaran; y a menudo se introducían correcciones en las medidas o pequeñas variaciones formales. Muchos dibujos tienen anotaciones como "Este es el elegido", o "Este modelo, que lo hagan lo antes posible".

Parte de los dibujos, que se deben a varias manos, son anónimos. Un grupo datable en los años veinte y treinta, de estilo más personal, está firmado por su autor, Salvador J. Díaz ${ }^{19}$, del que nada sabemos, excepto que tuvo un hermano llamado Tomás que dibujaba como él y que también trabajó para Apolinar. En contadas ocasiones figuran otras firmas, una de un

\footnotetext{
1814 de septiembre de 1940.

19 Sólo uno de los dibujos de su mano está fechado en 1923.
} 


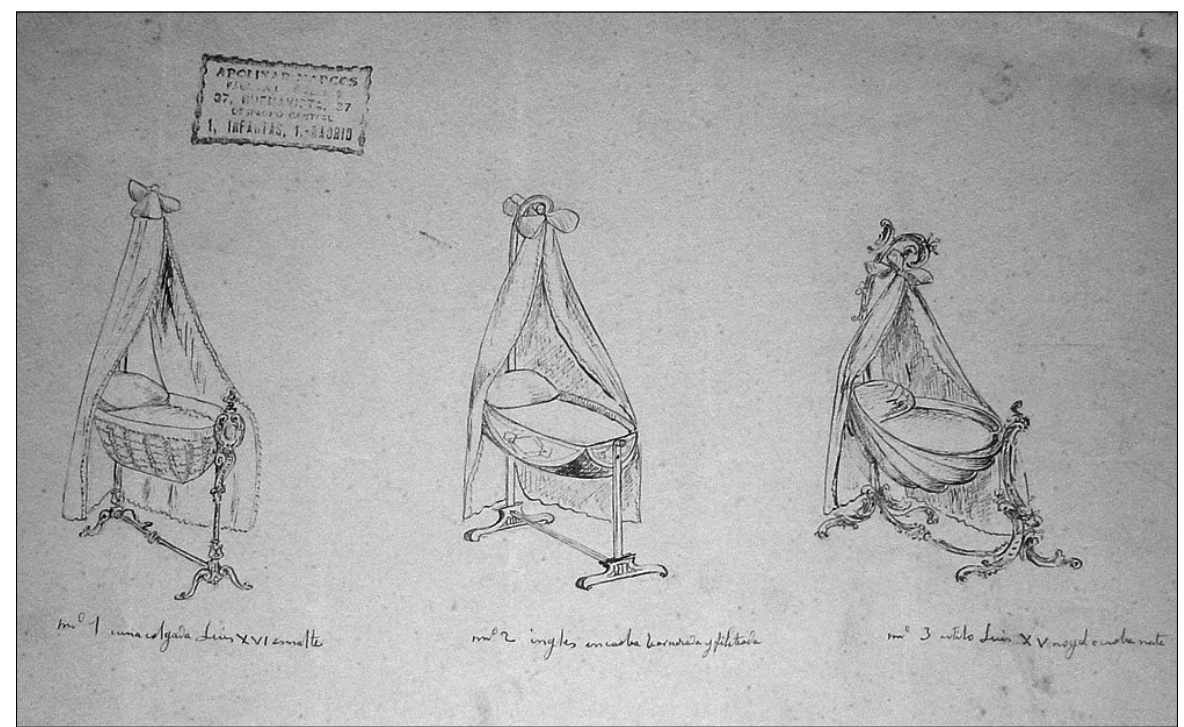

FiguRA 6. Boceto de una cuna en varias versiones para presentar a un cliente.

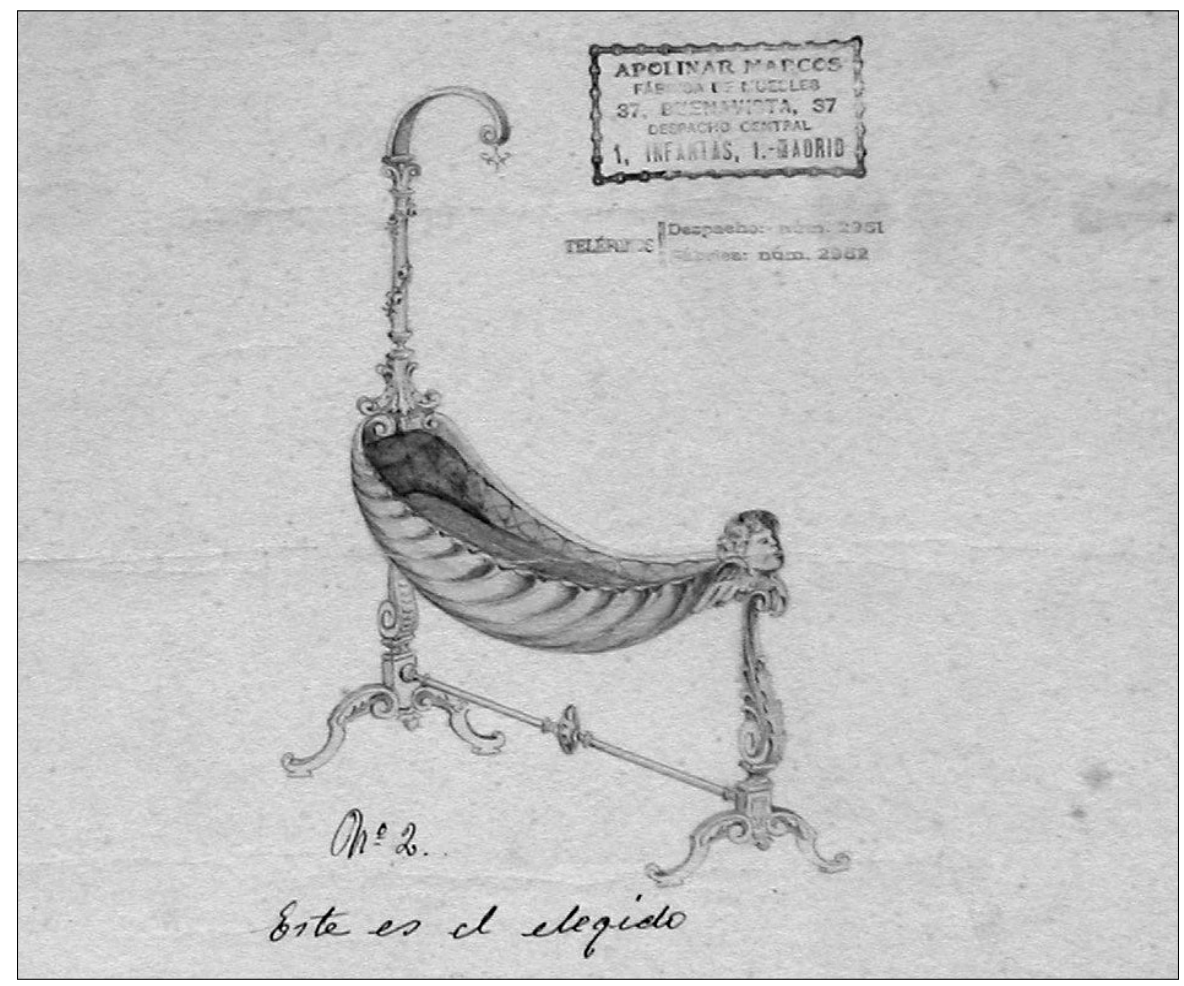

FIGURA 7. Versión elegida por el cliente. 
Joan Martínez que quizá corresponda al dibujo de un proveedor; también hay láminas con siglas (R.S.S., E.G., C.E.).

El proceso de creación y producción de un modelo empezaba por la búsqueda de inspiración en lo que estaba de moda, en España o fuera, siempre dentro de unos límites conservadores que raras veces transgredían el historicismo. Los modelos se buscaban en las revistas ilustradas de decoración, por lo que han quedado en el Archivo muchas hojas sueltas ${ }^{20}$ y algunas colecciones de láminas encarpetadas, como Mobiliarios completos ${ }^{21} \mathrm{y}$ Habitaciones amuebladas ${ }^{22}$. Este género de publicaciones, muy abundantes a partir de mediados del XIX, estaba concebido en parte para talleres y fábricas, a través de los que actuaron como agentes difusores del gusto. En el fondo Apolinar también hay fotos de otros fabricantes, algunas de las cuales sirvieron asimismo de ejemplos para su taller. Una vez seleccionados los modelos, las formas y las decoraciones, se dibujaban los proyectos que la fábrica se proponía materializar. Con toda probabilidad los dibujantes de la casa traducirían al papel las ideas de Apolinar, al que aconsejaría su Jefe de Taller, como era habitual. A partir de los dibujos, los ebanistas hacían

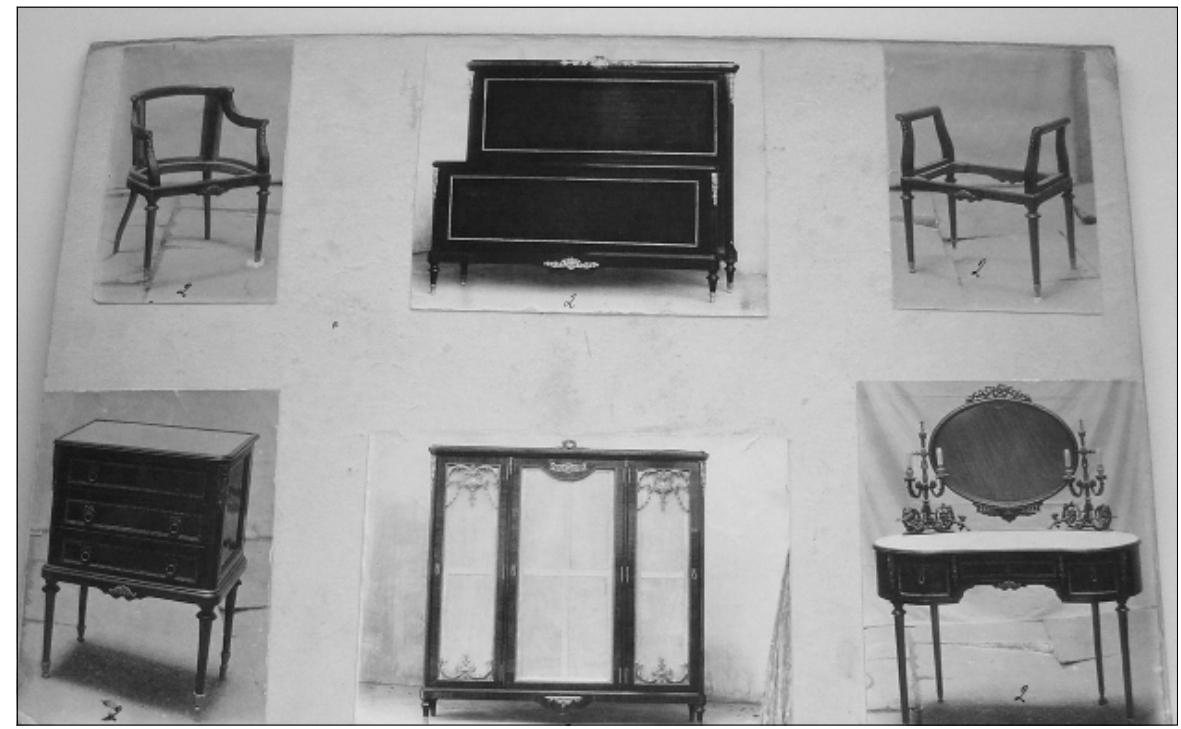

FIgura 8. Dormitorio Luis $X V$ realizado por el mueblista Román González a fines de los años veinte y comercializado por Apolinar (al dorso de una de las fotos, a lápiz: "de Román").

\footnotetext{
${ }^{20}$ Muchas de ellas son alemanas.

21 Serie II, Sucesores de J.M. Fabre y Caselles Moncanut Hermanos, 1935.

${ }^{22}$ Serie II, M. Bayés, Barcelona, s.d. (principios de los años veinte).
} 


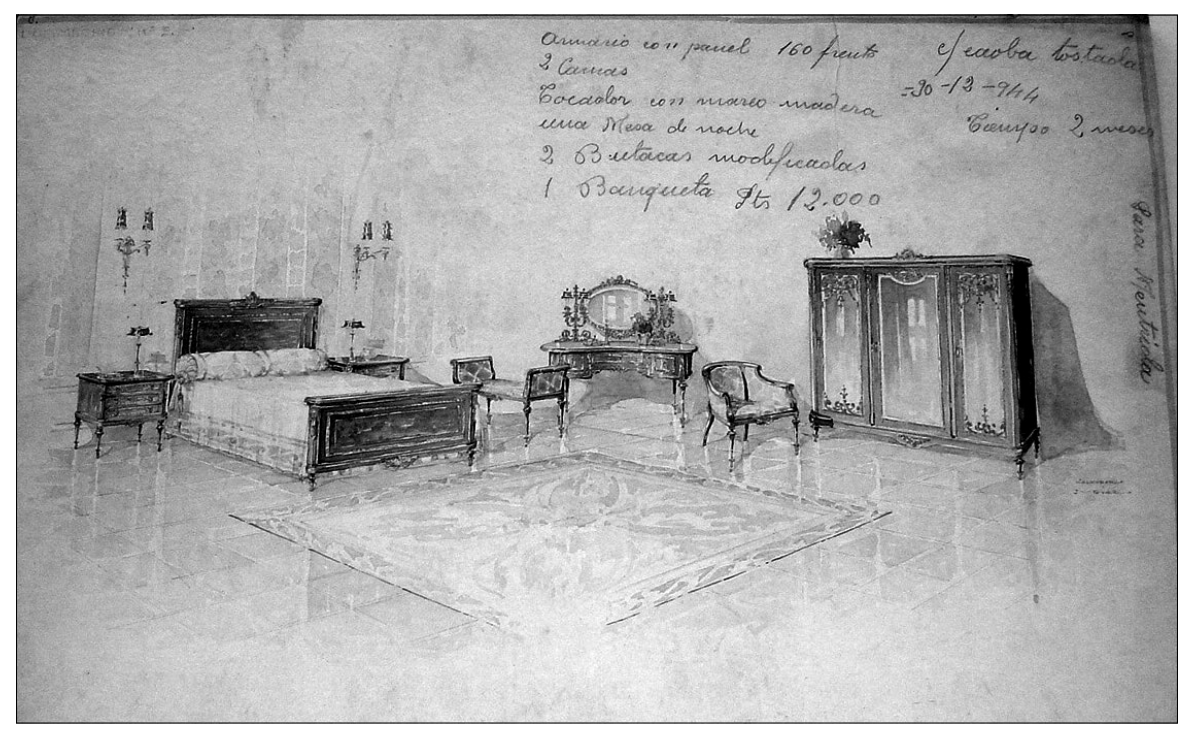

FIgura 9. El mismo dormitorio de la figura 8 dibujado por Salvador J. Díaz para presentar a la clientela de Apolinar.

los despieces en partes y elementos de armaduras y decoraciones que servían para dibujar plantillas a tamaño real. La observación anotada en el bosquejo de un biombo, "Me parece demasiado grande comparado con otro que tengo yo", y las descuidadas anotaciones sobre medidas y materiales que ensucian muchos de los dibujos, hacen pensar que las piezas se proyectarían primero sobre el papel, que después se harían las correcciones y que, finalmente, se construirían. Es posible que los muebles de menor importancia o complicación no necesitaran seguir todos estos pasos, y que con sólo dar indicaciones verbales o procurar una foto o una imagen al jefe de taller, fuera suficiente. El archivo guarda recortes de fotos y de grabados de muebles sencillos a los que se han añadido, a tinta, indicaciones como "en roble y tapizado", "en roble y cuero", que pasarían directamente a manos de los operarios. Es de presumir que muchos de los dibujos, sobre todo los de factura cuidada, se harían ya después de fabricado el primer mueble de un determinado tipo, para que fueran fieles a la realidad y pudieran mostrarse al cliente con todas las garantías; algunos se harían ex profeso para individuos concretos. Sin embargo, no existen grandes diferencias de concepción entre los diseños previos y los dibujos-catálogo. Hay otro tipo de ilustraciones, que corresponden a proyectos específicos, que son quizá los más espectaculares. Los mejores, muy bien presentados en papel de excelente calidad, son de mano de Salvador J. Díaz, del que se guarda asi- 
mismo un croquis en papel de seda, un apunte previo que, después de ser aprobado por Apolinar, serviría para realizar el proyecto definitivo.

En los proyectos decorativos se yuxtaponían piezas del propio Apolinar con otras de sus suministradores: en un álbum que recoge la propuesta para amueblar la zona de oficiales y suboficiales de todo un establecimiento militar - academia o cuartel_, en el que figuran despachos, sala de juntas, sala de fumar, sala de banderas y dormitorios, en estos últimos figuran las camas metálicas que se solían adquirir a José Puente ("Fábrica de camas de hierro") y a Eleuterio Guzmán ("Camas de bronce").

Muchos de los dibujos están marcados con números. Contrariamente a otros mueblistas, que numeraban correlativamente toda su producción, Apolinar parece que prefirió numerar por series, e incluso por proyectos, en los que a cada mueble se le asignaba una cifra, empezando por el 1. De ahí que menudeen mucho los números bajos, que se repiten de forma recurrente. Sí se debió de llevar un registro de tipo más general, o varios, por períodos, ya que en algunos proyectos figuran números superiores al millar.

\section{Proveedores y clientes}

Las maderas de esta etapa siguen proviniendo en parte de los bosques de la Sierra de Madrid, a los que se añade el haya de Piedralaves, distribuida por Pedro García Fogeda. A Venancio Crisóstomo se le adquiría un gran volumen de castaño, y el nogal a Balbino Moeda Illana. Quizá el almacén de maderas que procuraba mayor variedad era el de Eustasio Cepeda, del que constan entregas de especies habituales como haya, chopo, nogal, castaño y "roble liso", junto a "roble de malla", okume, caoba, "caoba Grand Bassam", caoba de Cuba y haya esterilizada. Durante estos años el auge de los chapeados plumeados y de las maderas de rica textura obligó a multiplicar las fuentes de suministro. En menores cantidades, Apolinar pidió a Viuda de Andrés Miera ("Maderas de Europa y América. Depósito en El Grao de Valencia") tablones de abedul americano.

Los muebles diseñados en casa Apolinar a veces eran fabricados por ebanistas independientes, es de suponer que por su baratura, por su especial pericia en determinados trabajos o por la saturación de encargos que se debía producir en algunos periodos. Esta forma de trabajar se comprueba gracias a una factura que la firma de Manuel Gómez remitió el 28 de julio de 1934, en la que se menciona "un comedor en madera de haya compuesto por un aparador, con repisa sin lona, trinchero, mesa cerrada según diseño enviado por Vd y seis sillas". Lacadores y rejilleros eran también trabajadores por cuenta propia. 
En 1920 Apolinar compraba mucho a otras compañías. Parte de estas adquisiciones estaban destinadas a completar la hechura de sus muebles, a guarnecerlos o a rematar sus proyectos decorativos. Durante los años veinte el Taller de Tornero Mariano García ("Se hacen toda clase de trabajos en madera, hueso y marfil") le procuró columnas, remates, pies, patas y piezas de torno de cierta complicación para sus muebles, por ejemplo, "colunas [sic] de perchero", pies de cama con y sin casquillo [ruedecillas], balaústres y "cebollas" de distintas maderas — las últimas sin duda de estilo Elizabethan, tan de moda por entonces-, "pies gordos y cortos" para meridiana, pies torneados para sillones, pies "torcidos" que también llama "ponpellanas", etc.

Los asientos, tanto los propios como los suministrados en esqueleto (sólo la armadura) o en blanco (sin tela de tapicería, pero henchidos y rematados con una tela blanca) por otros ebanistas, se entregaban tapizados al cliente, que podía elegir tela y pasamanerías dentro de una oferta estándar. Apolinar las encargaba a fábricas y distribuidores que procuraban los tejidos por piezas y por metros. Durante los años veinte recurrió a casas madrileñas: Tapicerias Peña, Rodríguez Hermanos ("Tejidos para muebles. Cortinajes de arte"), Antonio Tejero, A. A. del Valle, Sucesor de Hijos de F. y A. Rodríguez ("Proveedor de Palacio"). Desde fines de los veinte, coincidiendo con un aumento del volumen de negocio, comenzó a pedir a provincias, donde podía encontrar precios más convenientes para encargos más abundantes, y quizá géneros de aspecto más novedoso: desde 1928 a García Graciano, de Vitoria ("Grande Fabrique de Tapisserie" Londres-París-Vitoria), y a partir de 1929 a J. Ramón Blay, de Valencia ("Obrador de tapicería") y a otros de la misma ciudad o de sus alrededores como Joaquín Motes Estela ("Fábrica de tejidos de seda"), Ricardo Sada Moneo ("Fábrica de terciopelos labrados") y Viuda de Bernabé Rosell. En Barcelona recurrió a E. Navarro Roquejoffre y a la Casa De-Negri ("Fábrica de bordados mecánicos y a mano"). En casi todos adquiría telas por metros, sobre todo damascos de diverso tipo, terciopelos y panas. En la década de los treinta amplió la nómina de suministradores valencianos y catalanes, y extendió los encargos a Bélgica, a la Agemeene Fluweelweverij N.V., sita en Kortrijk, especializada en "moquette de coton", "shaft velours" y "Jacquard velours".

Con los metales ocurrió lo mismo que con los tejidos: Apolinar comenzó tratando con casas españolas para, a fines de los años veinte, iniciarse en la importación de guarniciones de Bocklenbeg, Motte $\mathcal{E}^{\circ}{ }^{o}$, de Ronsdorf (Alemania) — con los que contactó a través de los intermediarios bilbaínos Conrad \& Cia - que le enviaron regularmente "cerraduras de embutir", "asas de cajones", "escudos con entrada", "asas para puerta", "ruedas de sillón", maquinarias de reloj y sonerías, y llaves. Entre éstas últimas hay algunas con 
"aumento [de precio] por ser las esferas con inscripción 'Apolinar Marcos Madrid' a 7,50 pesetas", de diseño geométrico y desornamentado, acorde con la popularización de algunos de los presupuestos racionalistas entre las grandes industrias alemanas. También probó a importar, en 1935, "piezas corbateras herrenfreunde en niquelado" de la casa Gonnemann $\& C^{o}$, pero parece que el trato duró poco. En los años treinta, con la extensión del gusto por los metales plateados y cromados hubo un incremento de suministradores de metales de calidad, como el taller electroquímico de Luis Vivas Vázquez, que le entregaba barras de cortinas y anillas, o la Ferretería Hispano-Americana S.L., especializada en anillas, escudos, tiradores, bisagras y cerraduras "galvanizadas y plateadas". Además, aumentó los pedidos de piezas ornamentales, como los capiteles, garras (para pies), conteras (calzos para pies), apliques, canastillos, remates, marcos de tocador y de espejo y grecas de Vicente Martínez Ibáñez, de Valencia ("Manufacturas de bronces"), que destinaría a muebles de aspecto más tradicional.

Los cueros para asientos de sillas se adquirían, ya preparados, a Viuda de Manuel Amillo y a Juan Prida, ambos de Madrid, en cuyas facturas aparecen apuntes como el siguiente ${ }^{23}$ : "2 cueros de asientos para sillón, cuero de $1^{\text {a }}$ color avellana y 80 tachuelas". En 1935 Apolinar se atrevió con las imitaciones de piel, aunque no a gran escala, como el "Granitol" de $R$. $M$. Nosworthy, establecido en Barcelona y Madrid.

Parece que parte de los colchones de las camas se confeccionaban y se rellenaban en el taller, al que Hermógenes Egido ("Lana y colchonería") entregaba lana de vellón por quilos y por arrobas, miraguano, telas de colchón y "hechuras de colchones", y Francisco Igual Vila, pluma "blanca y gris". Los mejores somieres procedían, a partir de 1929, de Clemente Camarasa ("Fábrica de sommiers [sic] de madera y jergones de hierro"), que era, si damos crédito a la propaganda de su propietario "La más importante de Aragón. Exportación a provincias". Los vidrios y lunas de armarios y aparadores se fueron enriqueciendo a partir de las mismas fechas, que es cuando empiezan a aparecer facturas de vidrieras emplomadas de La Artística ("Esmaltes sobre cristal. Muestras transparentes") y de Cristal Madrid S.A. ("Espejos biselados, toda clase de vidrería extranjera de grandes dimensiones y de alta novedad. Vidrieras emplomadas y con armadura de metal").

Las bombillas "Philis [sic] vela" que imitaban la luz de las candelas eran de Vicente Zúmel, al que volveremos a encontrar más abajo.

Pero la mayor parte de los suministros son muebles acabados de otras firmas, que Apolinar comercializaba en su tienda. Parece que tenía un stock variable y moderado de los otros fabricantes, a modo de muestra, y que

\footnotetext{
${ }^{23}$ Factura de 11 de junio de 1925.
} 
solicitaba nuevos suministros cuando tenía encargos en firme de los clientes. Aunque la correspondencia es muy parca, dos cartas de $1931^{24}$ y $1933^{25}$ ponen de manifiesto que las solicitudes se sucedían en goteo, debido a la costumbre de introducir modificaciones en las medidas y los materiales de los modelos a capricho de cada comprador: "Le ruego que envíe una cama de $105 \mathrm{~cm}$ de modelo n. ${ }^{\circ} 215$ en color limoncillo, procurando que haga completo juego a lo último servido por Vd., que fue un armario, un tocador y una mesita, y tengo vendido dicho juego que entregaré mañana Dios mediante con una sola cama, y necesito dos"; "Formulo la presente para manifestarle que tengo un cliente que desea un juego de dormitorio para dos niñas, de madera de citrón [limoncillo], del modelo n. 9255 , pero haciendo el armario $15 \mathrm{~cm}$ más de frente [...] Y los muebles que se desean son los siguientes: armario de 3 cuerpos según encargo, dos camas para colchón de $90 \mathrm{~cm}$, una mesa de noche de $60 \mathrm{~cm}$, un comodín tocador [...] Lo que sí me permito rogarle es que procure poner todos los tableros que van chapeados de limoncillo, de buena clase, y un poquito más gruesos que los remitidos en los juegos que tengo en esta, porque en la actualidad, los dos juegos que tengo, están resquebrajados". La fabricación estandarizada en serie resultaba impensable con este sistema de funcionamiento.

El número de proveedores creció con los años. En la década de los veinte Apolinar trabajaba con una decena de carpinteros y ebanistas madrileños. Algunos eran silleros modestos, que le procuraban género más o menos corriente, como Francisco García, Francisco Guallart, Sillerias Segura y Ángel Asiaín. A ellos hay que añadir una ebanistería de Badajoz, Viuda de Francisco Guerri ("Grandes fábricas de muebles"), con la que tuvo una larga relación comercial que mantuvo por afecto o por costumbre, ya que el volumen de los pedidos, al principio muy crecido, no aumentó con el correr de los años. Otros suministradores tenían industrias más importantes, y mantenían negocios de características similares al del propio Apolinar, con catálogo propio, talleres y tienda; algunos se dedicaban también a los proyectos decorativos. C. Maximino Cerezo, Casa Aparicio y Andrés Alonso fueron los más destacados, de entre los que pareció preferir al último.

Desde finales de los años veinte aumentó la nómina de proveedores de muebles construidos. Algunos eran madrileños, como Román González ("Constructor de muebles de lujo"), Remigio Sapina Chornet ("Taller de ebanistería"), Francisco Cappa, Tomás Jacinto, Juan Mayor, Francisco Esquitino, Antonio Monterde, Leonardo Maderuelo, Román Palacios, Pedro Cartagena, y otros, de los que aún no sabemos nada; pero la mayor parte

\footnotetext{
${ }^{24}$ De 23 de septiembre, dirigida al mueblista Manuel Alfonso, de Valencia.

${ }^{25}$ De 5 de abril, dirigida al mismo.
} 
eran valencianos: Jaime Badía Bru, Juan Blat, Juan Camps, José Franco, Leandro Sospedra, Manuel Gómez, Viuda e Hijos de Murguía, José Alonso, Emilio Estrada, Ramón Sanchiz, y un largo etc. Muchas de estas compañías estaban especializadas en la realización de muebles de madera curvada, pero no aparece ninguno de este género en las facturas que enviaban a Apolinar, que prefería la sólida ebanistería tradicional. De vez en cuando, entre las abundantes y abultadas facturas de todos ellos, aparecen otras sueltas, más magras, de ebanistas a los que Apolinar quiso probar pero que no debieron gustarle.

Entre los suministradores los hay de dos tipos: los de taller modesto y los de fábrica importante. Los segundos tienen un catálogo amplio, que se manifiesta en los números asociados a los muebles (dormitorio 336, comedor 760, sillón de despacho $1034 \ldots$ ), números que son correlativos en muchos casos, y que van subiendo de año en año, revelando una incesante renovación de los diseños; las piezas de Santos Luque, de Madrid, y de Alonso y Cia., de Valencia, llegan a sobrepasar el número 1000 de sus respectivos catálogos. El de los mueblistas corrientes, si es que lo tienen, apenas llega a la cincuentena o, a lo sumo, al centenar de números. Facilitan tipos de muebles simples y no muy variados, fundamentalmente asientos y comedores. En los años treinta Apolinar recurrió preferentemente a las fábricas de mayores medios y catálogos más amplios que, aunque mantenían los nombres de sus fundadores, se iban acercando en cuanto a sistema de trabajo y organización a las sociedades limitadas modernas. Si los talleres de tipo tradicional le vendían la mercancía a la entrega, las fábricas se la cedían en calidad de depósito durante períodos limitados, tras los cuales satisfacía las letras correspondientes. Por si las facturas no fueran suficientemente reveladoras acerca de estos procedimientos, se conserva una carta de enero de 1934 en la que Tomás Jacinto Díaz ("Muebles artísticos") escribe: "Me es grato hacerle presentación de esta [factura] correspondiente al detalle de entrega del dormitorio Barroco moderno n. .60 , el cual se encuentra en su poder en calidad de depósito para su venta".

Con el transcurrir de los años Apolinar se fue decantando por una cierta especialización a la hora de elegir los suministradores. Si los de los años veinte eran ebanistas de tipo general, con posterioridad se aprecia un aumento de los que tenían alguna peculiaridad técnica, estilística o material. Los valencianos le enviaban muchas piezas chapeadas en maderas de rica textura, adornadas con los plumeados y los efectos de veta irregular que tan en boga estuvieron en los años treinta; en los documentos de Jaime Badia y de otros se mencionan "mallas", "rarezas" ${ }^{26}$ y maderas de raíz, y

\footnotetext{
${ }^{26}$ Maderas de fibra de efecto poco habitual resultantes de veteados irregulares.
} 
aparecen combinaciones efectistas como "sicómoro color nogal", "sicómoro imitación nogal difuminado" y "palma de caoba"; también figuran muebles tallados, con "talla rozada pulimento a brillo", como los de Bru. Otros ebanistas estaban especializados en determinados muebles: Antonio Prieto, de Madrid, en "bargueños de estilo Renacimiento español" y en "sillas de estilo español de balaústres"; la Fábrica de muebles de Las Tres Águilas de Francisco Esquitino, en armarios; la Viuda e Hijos de C. Murguía, de Vitoria, en burós (que en las cuentas aparecen elegantemente denominados "bureaus"). El mismo Apolinar trabajaba principalmente en juegos de comedor, de dormitorio y de despacho.

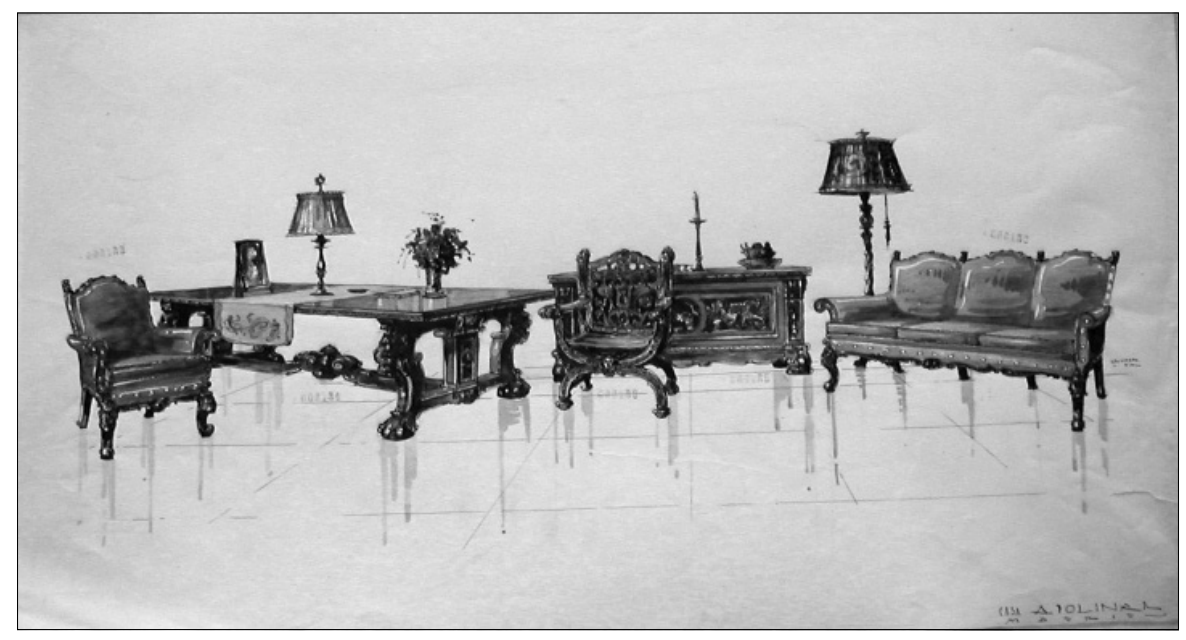

FIGURA 10. Despacho renacimiento, años treinta.

Por fin, a otros comercios acudía por piezas muy especiales: a la Ferretería Hispano Americana porque tenían juegos de poleas para cortinas y portieres; a Vicente Ramón Castelló, de Valencia, por sus pedestales para radio; a La Metálica, de Bilbao, por las "bastoneras de plata oxidada modelo n.ำ 10 GUERRERO Y ÁGUILAS", y por el "modelo METÁlICA en cobre oxidado", etc. También se registran encargos únicos, búsquedas de piezas o adornos poco frecuentes a demanda del cliente, y tan dispares como "un escudo bordado de Madrid de 34 x 27" pagado a Vicente Rosillo ("Fábrica de bordados mecánicos") en 1935, o una "mesa de cama Labernie cromada, modelo A" conseguida en el Garage [sic] Citroën de M. Negrete.

¿Cómo elegía Apolinar los muebles y los objetos de los fabricantes, sobre todo de los de provincias? Quizá los visitara, pero además las numerosas fotos que conservó en el archivo le sirvieron como referencia; la mayor 
parte son anónimas y de calidad regular, pero las hay de algún fotógrafo conocido, como Alfonso (Alfonso Sánchez), uno de los profesionales más prestigiosos de Madrid. La mayor parte ostentan los números de referencia de sus fabricantes. Alguna se ha podido identificar, como una "alcoba Luis XVI, n.. 7" o el "comedor Chippendale en caoba compuesto de aparador, trinchero, mesa con torno, seis sillas y dos sillones" que Román González facturó en $1928^{27}$, conjuntos de los que el archivo conserva la fotografía y la factura.

Sillas y asientos se encargaban también a talleres de tapicería, en particular los que requerían una labor de henchido de envergadura que superaba la importancia de las maderas. Se seguía así una tradición iniciada en el siglo XIX, cuando los asientos se fueron convirtiendo en pelouches, proceso que aprovecharon los tapiceros para convertirse en mueblistas y decoradores. Apolinar trabajó mucho, desde los años veinte, con Ramón Vergara ("Se conserva y reforma toda clase de obra de tapicería. Construcción de toda clase de muebles. Se cortan fundas"). También los tapizados dificultosos de cuero se confiaron progresivamente a especialistas, por lo que menudean en el archivo facturas poco importantes por trabajos puntuales como la que pasó Salvador Aulés "Por poner cuero de primera, lona y tachuelas a un sillón giratorio" 28 .

Por último, Apolinar compró adornos y objetos de diverso género para incluir en sus proyectos decorativos. Los más abundantes son las colgaduras confeccionadas, como los estores, cortinas y portieres (antepuertas), cuya colocación también se pagaba aparte: conceptos como "la colocación de cortinas" o "la colocación de huecos" (conjuntos de colgaduras para vanos) son recurrentes en las facturas. A esto se añaden las pantallas para lámparas de José Camps, o los bronces artísticos plateados y policromados de Francisco y Cía, composiciones que responden a títulos tan característicos de la época como "Invasión de los bárbaros", "Costumbres romanas", "Rendición de Breda", "Numancia", "Sagrado Corazón de Jesús", "Sarcófago egipcio", "Cervantes", "Gallina ciega [Goya]" y la inevitable "Cabeza de guerrero".

Estos datos contribuyen a aclarar un sistema de trabajo complejo, en el que un mueble podía pasar por varias empresas con nombre propio antes de ponerse en manos del cliente. Tomemos por caso la ocasión en la que el tapicero Ramón Vergara mandó una cuenta "por forrar un tresillo ynglés de Alonso en pana verde"29: Apolinar, bajo encargo, había pedido a la em-

\footnotetext{
27 Facturas de 10 de diciembre.

${ }^{28}$ Factura de 9 de agosto de 1924.

29 De 15 de diciembre de 1923.
} 
presa de Andrés Alonso ("Arte Decorativo. Ebanistería y tapicería”) un sillón a la inglesa, suponemos que en esqueleto o en blanco, que envió más tarde a Vergara para que hiciera un trabajo que se hubiera podido completar en la primera. Estas combinaciones se debían, sin duda, a razones económicas unas veces y de búsqueda de una determinada calidad otras, pero hemos de suponer que también eran fruto del deseo de ofrecer un producto diferenciado, con sello propio, que se obtenía diluyendo la personalidad de los otros fabricantes al yuxtaponer sus respectivas habilidades. Este juego era compartido por todos los industriales de mediana escala. Si un competidor ofrecía buenos precios y calidad ¿por qué no aprovecharlos en beneficio propio? El concepto de la competencia incluía por entonces algunos rasgos de colaboración que atemperaban la pura lucha por el mercado para beneficio de pocos. Todos cabían en este entorno de pequeña y mediana empresa, en el que la multiplicación de talleres fomentaba la expansión. El trato directo con el cliente para ofrecerle exactamente lo que necesitaba, y la cuidadosa organización de un complejo y equilibrado entramado de encargos a otros fabricantes para atender con precisión a la propia clientela, eran la garantía del éxito.

Los estilos

Entre 1920 y la Guerra Civil se mantuvo el tono historicista. El rococó se fue abandonando, pero los estilos ingleses se mantuvieron, sobre todo aquéllos que se extendieron en Inglaterra a partir de los años setenta del siglo XIX: el Elisabethan, el Queen Anne, el Georgiano, el Sheraton eduardiano y, por encima del resto, el Chippendale, llamados aquí de todas las maneras imaginables: elizabon, chipendal...

Los más frecuentes son los muebles "españoles", estilo entre renacentista y barroco, muy sobrecargados de tallas, realizados sobre todo en oscuros nogales o en maderas "imitación de nogal". Todas las tipologías se sometieron al dictado de "lo español", pero fueron los bargueños, que Apolinar no fabricaba pero que encargaba a la Casa Alpema y a Antonio Prieto, los arcones, las jamugas, los bancos y los percheros (o "perchas", o "gabaneros") los que mejor adoptaron el lenguaje nacional. Las bastoneras de Talavera con águilas de Jaime Forné Comas y de otros ceramistas los complementaban a la perfección. Por 745 pesetas se podía adquirir en 1929 en la Casa Apolinar, a la que se lo había suministrado Santos y Luque, "un banco estilo español E978, un gabanero lira estilo español E998, dos mesas redondas estilo español E1048, un perchero estilo espalo E1077 y un bargueño estilo español E1098".

En estos años lo calificado de "moderno" es el Art Déco, de líneas 
geométricas domadoras de las vanguardias, texturas lígneas ricas, tapicerías claras y brillantes de colores entre los que predomina el salmón y metales plateados, en general niquelados. El taller de tapicería Valentín González sirvió en 1935 "dos sillones cubistas con almohadones"30 y José Martínez muchos muebles con "pata de escalones".

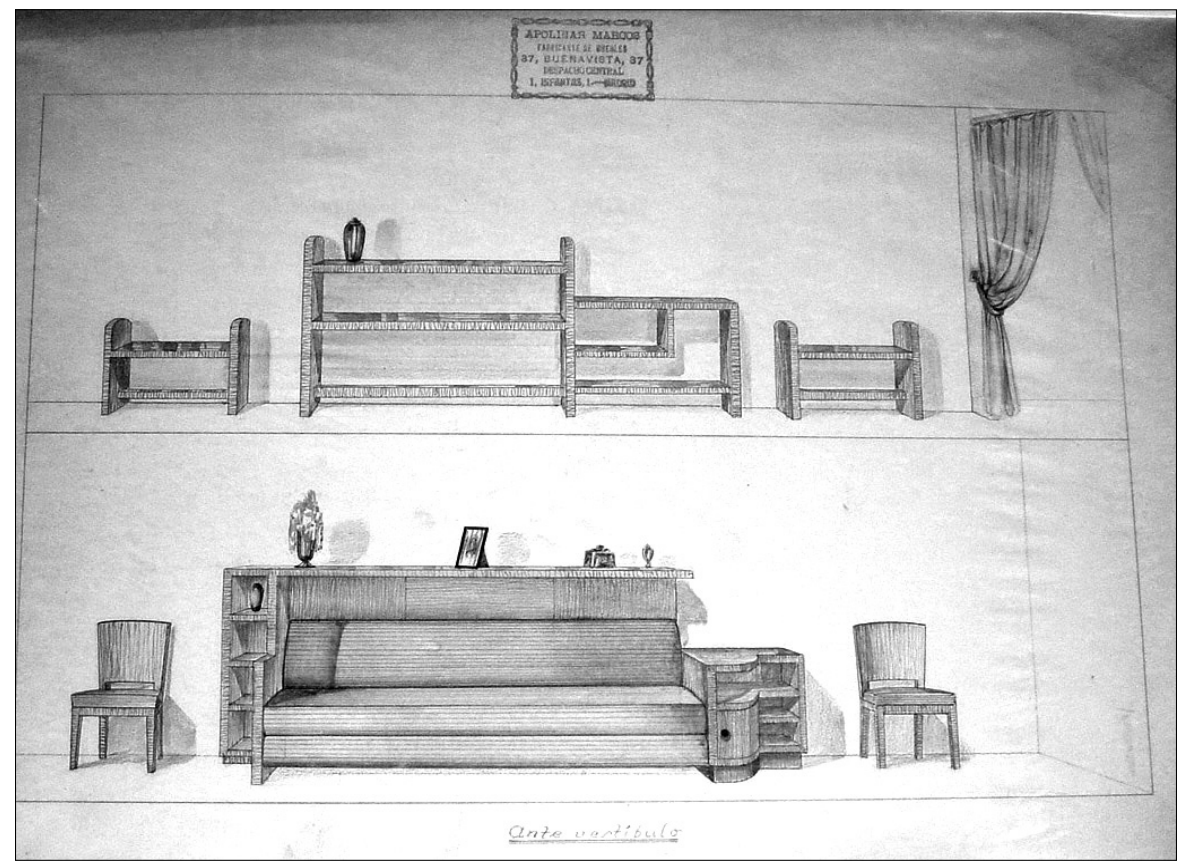

FIgURA 11. Sala art déco, años treinta.

La empresa Rolaco, de Luis Feduchi, había introducido los muebles de tubo metálico del Movimiento Moderno en Madrid. Apolinar, y quizá otros mueblistas, no tuvieron más remedio que imitar sus radicales innovaciones, si bien tímidamente y pactando a veces con la tradición. Para ello adquirió en 1934 "tubo de acero" a Viuda de Subero , pero prefirió encargar las piezas ya manufacturadas a otros industriales que contaban con infraestructuras más adecuadas para la manipulación de materiales industriales, como Francisco Cappa, al que pidió "un aparador de haya barnizada tipo Rolaco" en 1934, o Enrique Juan Castell, de Valencia, al que compró en 1935 un "tresillo asiento elástico, respaldo con muelles, con tubos de metal cromado, pulimentado en color nogal, con talla [...] y mesita de centro a juego". El mis-

\footnotetext{
${ }^{30}$ Factura de 29 de noviembre.
} 
mo Cappa le suministró en 1935 dos sillones Morris que, aunque relativamente comunes, seguían considerándose innovadores.

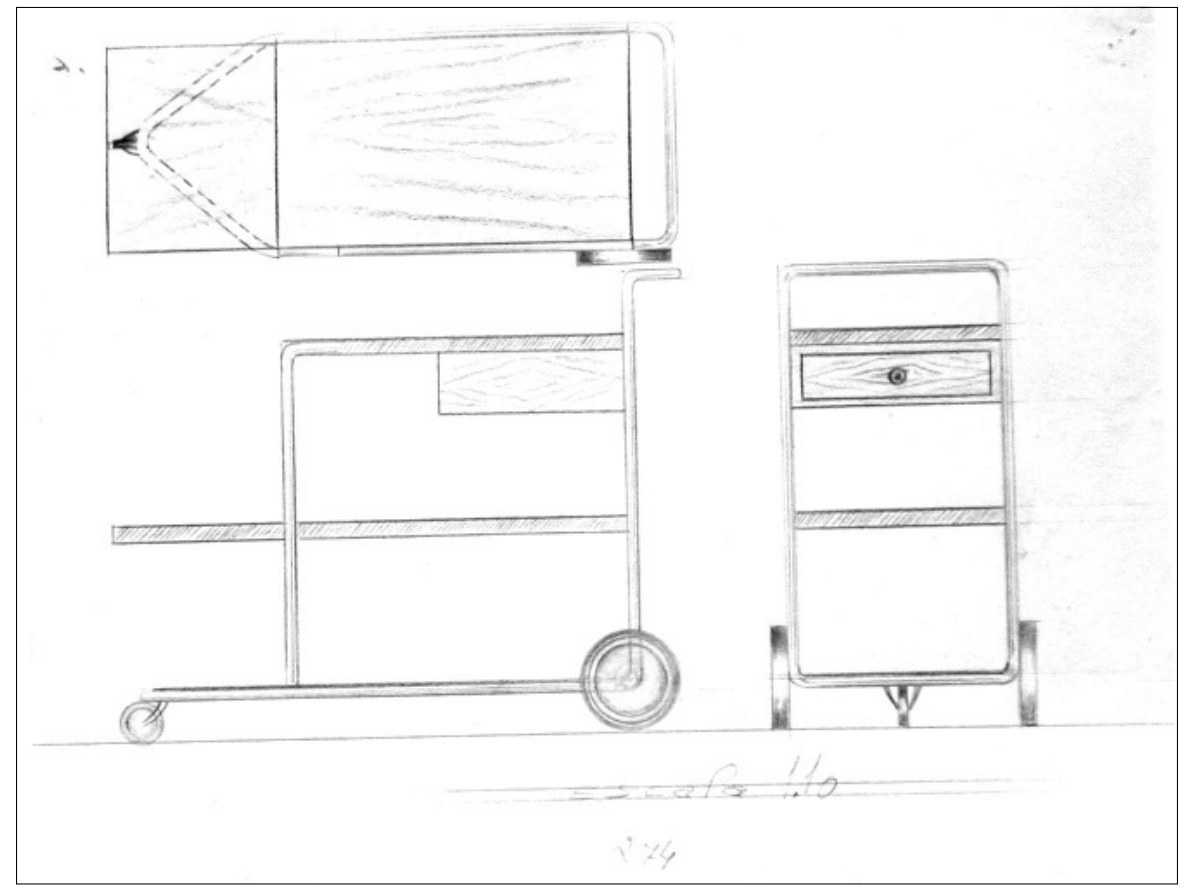

FIGURA 12. Mesa auxiliar "tipo Rolaco", años treinta.

\section{Los clientes y los trabajadores}

Pocas noticias se tienen sobre los compradores, gente acomodada en general, entre los que se encuentran algunos nombres conocidos como Diez de Rivera o Herráiz, que puede ser el mueblista. Estos y otros se recogen en las cuentas que pasa, en los años treinta, Francisco Caamaño, dependiente que trabajaba a sueldo y a comisión para Apolinar. Al sueldo, de 250 pesetas, se suman cantidades de unas 150 sobre un monto total de ventas de más de 30.000. Este Caamaño figura en un Libro de matrícula de operarios mantenido entre 1940 y 45, en el que se anotan los restos del abundante personal de la preguerra. Por estas fechas sólo quedan cinco empleados, dos dependientes, dos mozos y un individuo del que no se especifica el oficio. 


\section{Difusión y publicidad}

Apolinar Marcos fue consciente, como la mayor parte de los empresarios de su época, del poder de la publicidad como medio de atracción de la clientela. En la prensa del primer tercio de siglo es habitual encontrar inserciones de la firma cuyos textos se adecuan al perfil de los lectores de cada periódico. Las publicaciones son las principales de la época: Vida Económica, La Tribuna, El Heraldo de Madrid, La Correspondencia, El Universo, El Correo Español, El Imparcial, ABC, Ingeniería y Arquitectura, El Diario Universal, El Eco de Alcalá y El Pueblo Manchego. Existe un muestreo, que se realizó en los días de la I Guerra Mundial (hacia 1917 o 1918), que reúne recortes encolados, en las hojas finales del libro de contabilidad de 1908-1909. Una mano cuidadosa ha pegado ordenadamente varios anuncios, a los que ha adjuntado una cartela pulcramente escrita con el nombre de la publicación, el precio de la inserción —que oscila entre las cuatro y las casi nueve pesetas - y la frecuencia de la misma — días alternos, hasta quince al mes-. La inversión total resulta bastante respetable.

En general, Apolinar se presenta en los anuncios con un perfil alto y medio alto, aunque la palabra "lujo", que menudea en sus textos publicitarios, es un reclamo que pretende tentar a un amplio sector de la burguesía, a la que se anima a elevar su nivel de vida y a mejor parecer adquiriendo los artículos de la casa. En Vida económica la inserción dice: "Establecida esta casa y dedicada con especialidad al mueble de lujo hace veinte años, invita a su distinguida clientela a visitar su Gran Exposición"; en El Pueblo Manchego, en cambio, habla de "baratura, elegancia y buen gusto"; y en Ingeniería y Arquitectura presenta sus muebles como "los más fuertes, los más lujosos, los más baratos".

Asimismo, Apolinar se anunció en otros soportes, como el programa que se ofrecía con motivo de los conciertos que la Banda Municipal interpretaba en el Teatro Español, y en postales de distintos tamaños con reproducciones de piezas, en alguna de las cuales ofrece el "arreglo y restauración de toda clase de camas", y especifica: "Nuestros barnices dorados son a fuego". Buena calidad, pues, a precios no exactamente asequibles pero sí posibles de alcanzar haciendo un esfuerzo.

\section{BIBLIOGRAFÍA CITADA}

Fondo documental "Apolinar Marcos" (veinte cajas y carpetas, y un libro de cuentas, sin inventariar). Archivo de la Fundación Fernando de Castro. Asociación para la Enseñanza de la Mujer. 
Alzola y Minondo, P. 2000 [1892]. El arte industrial en España. Bilbao: Imprenta de la Casa de Misericordia.

Anónimo. 1895. "La historia del mueblaje". Almanaque Bailly Baillière 1895. Pequeña enciclopedia popular de la vida práctica. Sin paginar.

Catálogo oficial especial de España 1888. Exposición Universal de Barcelona. Barcelona: Imprenta de los Sucesores de N. Ramírez.

Exposición Nacional de Industrias Artísticas, e Internacional de Reproducciones 1892. Barcelona: Imprenta de Henrich y Cía.

Exposición Universal de Barcelona. Catálogo razonado de los objetos expuestos por el Cuerpo de Ingenieros de Montes 1888. Madrid: Imprenta de Moreno y Rojas.

Habitaciones amuebladas. Serie II. S.d. (principios de los años veinte). Barcelona: M. Bayés.

Mobiliarios completos Serie II. 1935. Barcelona: Sucesores de J.M. Fabre y Caselles Moncanut Hermanos.

Fecha de recepción: 14 de febrero de 2008

Fecha de aceptación: 15 de junio de 2008 